\title{
A Systematic Review on Cloud Computing and its Security Issues
}

\author{
Pooja Nagpal \\ Assistant Professor \\ Department of Computer Science Engineering, \\ Amity University, Gurgaon, \\ Haryana,India poojabatra9@gmail.com
}

\begin{abstract}
Over last decade internet is grown rapidly. Today we are in the era of cloud computing. Cloud computing is just not a concept it is a service delivered from huge datacenters which are called clouds. Example of these services is storage, resources, networking and many more. Some big corporate cloud service providers are Microsoft Azure, Amazon, Web services and Google cloud. Now day's concept of cloud is very popular in IT as well as in research fields. In this paper concept of cloud computing will be discussed in detail along with various issues. Issues will comprise security and privacy concerns. Security and privacy issues are highlighted in above section because security concern is the main problem in adoption of cloud usage. Consumer is sharing his confidential data and also using resources where he may share his company's information. So assurance of security is very essential to all consumers who are going to adapt cloud services. Also characteristics of cloud computing are detailed discussed here because to enable the availability of scalable IT resources is driven by defining characteristics. Further architecture of Cloud computing will be discussed which will help us in getting the conceptual framework of cloud computing.
\end{abstract}

Index Terms: Cloud Computing, Azure, Security Issues, Amazon.

\section{INTRODUCTION}

In this changing word business demands are also changing. Existing traditional models are not flexible enough to fulfill ever changing demands of business. So the best alternative solution to this problem is Cloud computing which can not only provide flexible but also dynamic delivery solutions. Cloud computing provides massive scalability and associative capabilities. Companies are able to use new services which were earlier very expensive. Overall view of cloud computing is shown in following figure1.[1]

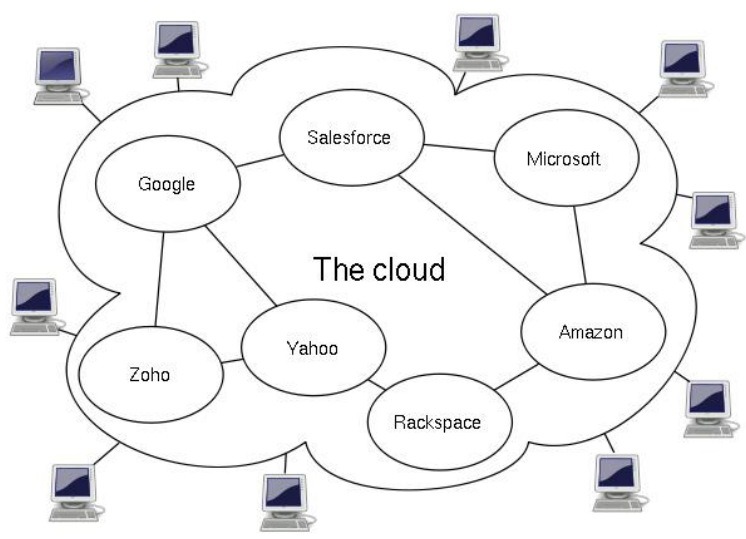

Fig1 Cloud Computing and its service provider (Mansur et al.,2011)

Organization of rest of the paper is like as follows: In the next section literature of cloud computing will be discussed which involves exact definitions of cloud computing for better understanding of concept. Further Characteristics and issues will be summarized

\section{LITERATURE REVIEW}

Most of the major IT companies have given various definitions of cloud computing though white papers. Plumber et al.[2] says In cloud IT enabled services such as Infrastructure and software can be provided. It is an alternative way to use other It delivery models approach.

According to Buyya et al.[3] Consumers according to their need for It infrastructure and software services may use it by paying few amount. According to NIST definition by P.Mell [4] essential characteristics of cloud computing are defined in efficient manner.

Cloud management will be discussed which requires supporting hardware and management software. In this section we describe work that helps building cloud offerings.

OpenNebula which is a virtual infrastructure and Haizes known as resource lease manager are the tools used for managing the clouds are discussed by Sotomayor et al. [5] .There may be any kind of virtualisation platform but OpenNebula presents all resources in a one go. It is also responsible to manage resources according to policies. Accordingly it allocates resources. Allocation policies like deploying to other cloud and prioritisation is also discussed in this paper. Requirement of applying policy scheme is only happen when demand ration is more than supply. Resource providing problem is also dealt with Haizea tool which is known as resource lease manager. With the help of this tool by analysing high demand resources are allocated in advance so that prompt demand can be fulfilled immediately. Both the tool can work together to provide resources on time. 


\section{International Journal of Research in Advent Technology, Vol.7, No.5, May 2019 \\ E-ISSN: 2321-9637 \\ Available online at $w w w . i j r a t . o r g$}

According to Song et al. [6] IBM data centre used hierarchical setup to extend their cloud-scale data centres. They named it blue eyes management software. It provides multi server facility. When there is fault in one server other server will provide information because management information was duplicated on the other server to provide reliability. It provides not only dynamic load balancing but also shows better performance and reliability too. Blue eyes architecture provides solution to scalability issue.

Vishwanath et al. [7] presented enhanced shipping containers for data purpose. They also described its architectural view. Their model provides better performance, reliability, less cost. In this paper Methods to select particular policy to adopt containers is described. A cold note is marked for containers which are not working or failed to work due to some reason. This failure time is calculated through Markov chains and further Markov chains are extended to Markov reward models. This is performed on real time failure data that is captured in real run time environment. Here exponential failure time is assumed. But what happens to shipment container? Private clouds can be packed in these containers and are ready for sale. For performance and cost, these Markov chains are extended into Markov reward models. These happen under the assumption of exponential failure times, and need to be evaluated against real data. The shipping containers could be used for selling private clouds in a box.

As the internet era is growing, data is also increasing resulting into growth of size of data centers. So Sriram [8] addressed scaling issue in his work. Normal failure causes problems and it is very tough to predict failure .In this paper performance is calculated by incorporates occurrence of failures and these failures are predicted in prior by calculated number of sheer components. This approach works only for big data centers. It does not work efficiently for small data centers because middleware layer does not support small applications.

Every consumer according to their applications have different quality of service requirement. This quality architecture is discussed by Buyya et al. [9]. This tool kit is called CloudSim which provides modelling as well as simulation. Here one or more virtual machines are created which are mapped to different data centres which prefer simulation of data centres also. To provide reliability migration of virtual machines also occurs. Cloudsim is mounted on Gridsim simulator which deals with scheduling of applications. In this way performance is calculated of service provided by cloud. There is obvious impact of virtualisation on performance.

There is need of managing cloud infrastructure too. Need of maintenance like placing patches on defaults, repairing and replacing faulty things, updating databases and services etc is always there in big setup. In this paper change management techniques are discussed. A proactive energy saving technique is introduced in this paper which enables lower consumption of energy. In this paper load consumption is calculated. Load increases as the number of working servers are increasing. Not working and faulty servers are not in the list of load as they are not using any load. This is the main strategy for change management. This load is derived from service level agreement layer. Cloud computing contains elasticity in nature and that is counted as benefit of cloud approach. But it will create in above mentioned approach. Due to elasticity frequent shuffling of servers is there but not working servers were not there in the load list. Suddenly they should be involved in list for accuracy of calculation. It creates a big bottleneck.

So far in spite of new topic there is lots of research on cloud computing and we have tried to discuss the work which is done till now in above mentioned area. Definitions were given to clarify the concept of cloud computing. Further characteristics were discussed to give base for further elaboration of concepts. Architecture of cloud was detailed to understand any implementation work done in cloud approach. In architecture 3 layer systems is discussed. Various issues and challenges are explored which act as shortcomings of cloud computing. Threats to security make it vulnerable. Management of cloud services is very necessary. As data grows maintenance issues increases. Complete literature is discussed on management issues, How to allocate resources, Problems in allocation, Lower consumption of energy etc.

\section{ISSUES IN CLOUD COMPUTING \\ 3.1Security concern}

We are saving our confidential data at a place which is not controlled by us, Is not it threatening. Security of data is the biggest concern in cloud approach. There are threats like virus attacks and hacking of data. To provide confidentiality to data encryption methods are used.

\subsection{Data Integrity}

Data Integrity relates to changed data without permission. That means consumer does not get actual data. There are number of users that may be using same services and resources. Different users may have different rights regarding data integrity. So there is possibility to change of data which can be solved by digital signature technique. Even there are many techniques which are updated version of digital signature

\subsection{Legal Issues}

Cloud computing is adhered with many laws like privacy and security laws and these laws vary from country to country irrespective of where data is located so it creates problem while adopting services of cloud. 
International Journal of Research in Advent Technology, Vol.7, No.5, May 2019

E-ISSN: 2321-9637

Available online at www.ijrat.org

\section{CURRENT PRACTICES IN CLOUD COMPUTING}

Internet is growing big so as data increases. In traditional approach everything was saved on your computer. Any resource needed, it was available on your system. But what will happen if network grows and number of people also increases. Cloud computing is the solution to this problem. It gives access to various hardware, services and software at small cost. There are four types of clouds which are described as follows. It will provide help to user to opt for better choice for implementation

\subsection{Personal Cloud}

In a personal cloud all the services are maintained by either of yourself or some other company you hire to maintain your cloud. Benefit of this approach is reduced security risk. Everything is in your own hand.

\subsection{Common cloud}

When a personal cloud is accessed by number of organisations or group of communities with same concerns. For example sub organisation in different regions can use common cloud but having privately secured server which will provide secure access to services.

\subsection{Public cloud}

Public cloud is open to all internet users. Here services are available off site and can be accessed though browser. Benefit of this cloud approach is elasticity and reduced cost. But user may have to compromise about security.

\subsection{Fusion cloud}

As its name suggests it is a mix of both clouds i.e. public and personal. In the same way it shares benefits of both approaches. Different approaches can be used according to requirement of consumer.

\section{WHY CLOUD COMPUTING IS SO POPULAR?}

\subsection{Money saving}

Rather than purchasing our own hardware, software, storage solutions, services same can be availed at less cost. In reducing cost many factors will work such as

- Maintaining cost of hardware and software will be reduced

- No salary to skilled staff

- Due to availability of services at each time cost reduces

- Low energy consumption yield to lower the cost

\subsection{Flexibility}

According to ever changing requirements and demands of business cloud computing provides flexibility to do business. It saves time which you were going to devote in purchasing and maintenance.

\subsection{Data Storage}

There may be possibility that you don't have enough storage to maintain your data and even data may be lost due to any natural disaster. There may be any type of harm to your data but in cloud environment you will get your data at any time and also store millions of data and more. It will save your productivity and also give productivity to your business.

\subsection{Be Updated}

If you are accessing cloud services no need to bother about latest and updated version. If you are subscribed for the same your system will be updated automatically.

\subsection{No Maintenance}

Now you do not own any software, service or hardware. You just need to pay some rent and everything will be organised and managed for you. So no need to take overhead of maintaining the things. Some third party is doing this for you.

\section{BUSINESS MODEL}

Here Business IT model of cloud computing will be discussed as per Pearlson et al[10].This model consist of two views. First one is business demand and second one is IT supply. This model will show iterative path where basic requirements will be fulfilled earlier. As the name of both views suggests, demand shows the requirement of services and software from consumer and Supply yields to fulfil that requirement. Model consists of three layers which depicts $\mathrm{S}$ shape curve. These three layers are efficiency, effectiveness and transformation and all three relates to business.

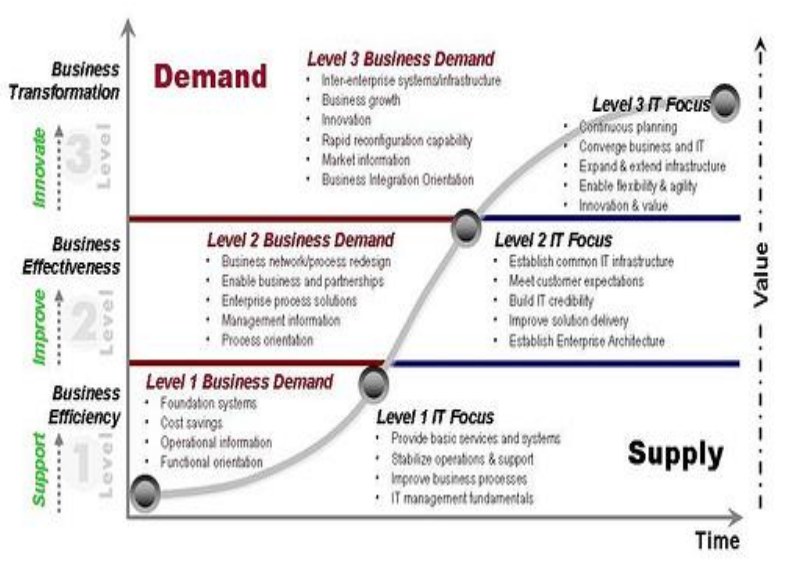

Fig 2. The Business-IT Maturity Model (Pearlson \& Saunders, 2007)

Basically a model is given to trace framework which will further used to map implementation. Four factors are clearly derived through this model like less cost, growth of business, increase in asset, competition advantage. As we have discussed that model is categorized into three layer where first layer efficiency derives from less cost and maximum output. Second layer effectiveness layer provides IT infrastructure and provide enterprise solutions by creating enterprise architecture which helps in better solution delivery and customer satisfaction. Customer gets unlimited services at any time. Third layer transformation includes continuous planning like 
allocation of resources, planning for those customers which are further providers and providing services to other customers. It also involves convergence of business and IT which results in better business growth. Some business companies expand their business here in the form of expansion of infrastructures.

Cloud computing allows you to access your data and programs outside of your own computing environment. Rather than storing your data and software on your personal computer or server, it is stored in 'the cloud'. This could include applications, databases, email and file services.

\section{WORKING PROCEDURE OF CLOUD COMPUTING}

To get better idea of cloud computing working of same should be discussed. Dominique Vernier [11] discussed cloud's working. Basic infrastructure to show working of cloud is given below in figure 4 Infrastructure like three layers IaaS, PaaS, SaaS supports every type of clouds.

Further there is requirement of an operating system which will be required to deploy required service. Operating system services will provide the same to consumer. Like an accounts manager Business services will accept request for services and will generate invoice for services. Amount for the services will be depend upon service providers that what is the policy of that service provider to charge for services. For some companies it depends upon number of user using any particular service, for some number of software or hardware used, for some time limit matters i.e. for how much period a particular service is used.

Cloud service consumer component provide interfaces to cloud service users. Interfaces are different from different service provider. One more component is there called cloud service creator. Function of this component is to provide tools for the services. As per requirement different number of user uses different tools at same time.

Now procedure of using cloud services will be detailed here. First of all consumer opts for his service provider. Some of the famous service providers are Amazon, Microsoft and Google. All service providers have different policies about payment. After selection of service provider user creates account on the portal and select type of cloud he wants to use. After registration login occurs and cloud service component is used to order for service. Now cloud service provider provides the service asked by the consumer. Service may be of any tool, software, hardware etc.

BSS will accept the request. If request can be serviced then asked for payment. Payment policy can be different for different service providers. After that service will be provided. Services are like renting options. After the completion of particular time as mentioned in contract subscription will be generated according to consumption of services.
Cloud computing approach has many benefits that is why it is preferred over traditional web hosting approach. It not only provides data storage solutions but also hardware, software solutions on less cost. Provides more flexibility, scalability and elasticity to business. It gives growth to business if IT and business are merged together.

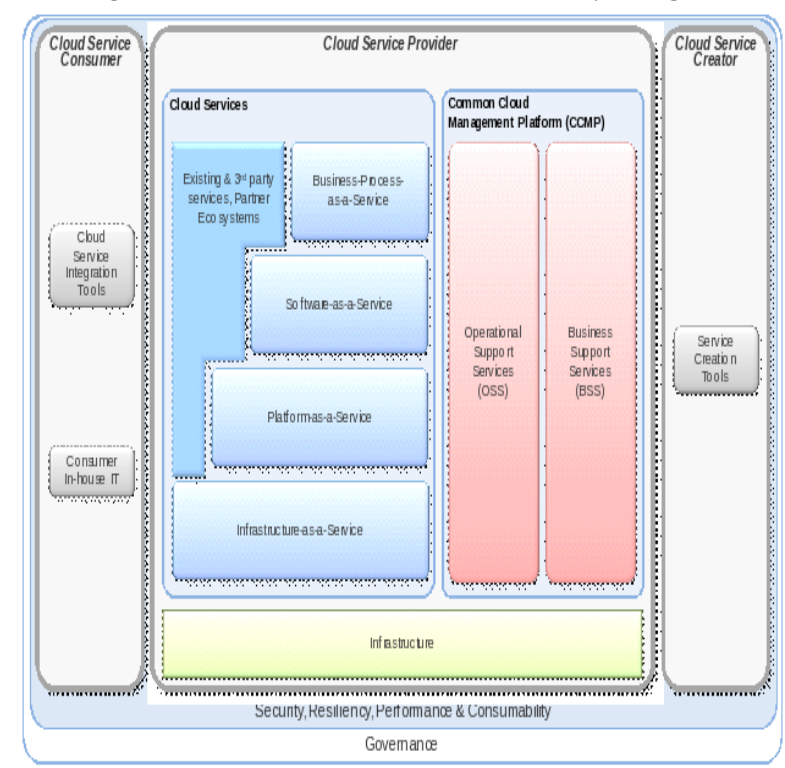

Fig 3. www.ibm.com/blogs/cloudcomputing/2014/02/07/how-does-cloudcomputing-work[2014][11]

\section{COMPARATIVE ANALYSIS OF EXISTING AND CURRENT PRACTICES}

As discussed by Leadingedge [12] there are lots of factors on which we can differentiate cloud computing and traditional IT infrastructure approach. Prior to Cloud computing IT industry was using traditional IT infrastructure. In that approach one remote server is maintained and several adjoining hardware are installed. All systems are connected through a network.

So to increase data storage Companies have to buy additional hardware and services also as per demand. Adjoining software along with hardware is also required for further functioning that would also add to cost. Additionally hardware and software failure cost also incur.

But when it comes to security traditional approach is better because every hardware and software is in company's own hands. Basically tradition infrastructure is a customised solution for applications running on different domains..

In Cloud computing all servers, software, services are hosted on cloud thus creating virtual environment between different servers. So no need to purchase those services and software as we were doing in traditional approach.

Cloud environment contains more elasticity than traditional approach. When one server fails another server takes its loads and hence efficiency increases. But in prior system they have limited capacity. 
International Journal of Research in Advent Technology, Vol.7, No.5, May 2019

E-ISSN: 2321-9637

Available online at $w w w . i j r a t . o r g$

Cloud approach provides more scalability in comparison to traditional approach. As it have unlimited storage and more resources. In previous approach limited no of resources, limited costs that does not gives you scalability and flexibility in work. Further comparison can be done on maintenance issue. In cloud environment maintenance is quite smooth because service provider is doing the same and he is going to be paid for these services. In case of traditional approach a single person that is hired by company is going to handle all maintenance related issue which is very troublesome task.

Security concern is the biggest issue need to be discussed .As data is open or we can say it is external storage so threat to data is more in cloud approach. In traditional approach data is stored internally so less chances of data stealing and corrupting.

\section{CONCLUSION}

The very first thing comes in the mind when we think about cloud is white and fluffy cotton like thing. It is kind of metaphor for computing. Cloud Computing is a service that can be availed by paying some amount as rent. This service may include storage space, networks, software, hardware etc. You will be able to share pool of services and resources. You don't have any need to worry about any software . hardware cost or maintenance. Any third party will do this for you. It will be available at any time as per requirement. Different companies provide their clouds for example Google, Microsoft, Amazon etc. These are the some renowned sources. Every company has its different interface of cloud to deal with IT companies which are customer for cloud provider. Some provides easy and attractive user interface for ease of developers to use services. Every consumer uses its services according to their requirement. Those who require for application services will for Software as a service approach. If customer wants to create its customize application then he will opt platform as a service option. If customer's requirement is a big business like renting out its own services then he will go for infrastructure as a service approach which is the most important or backbone of whole structure of cloud computing. In traditional approach everything was connected through server. Limited resources, more expensive, less elasticity and flexibility, less scalability but still more secure. Everything is in your own hands. But yet cloud approach is more preferable. Although cloud services provide solution for security issues yet not too much reliable. In today's market business of cloud is of around 140 billion dollar .It depends upon the customer needs. If he is ready to compromise on security grounds this approach is like heaven.

\section{REFERENCES}

[1] Mansuri, Anwar Mohd., and Prithviraj

Singh Rathore. "Cloud Computing: A New Era in the Field of Information Technology Applications and its services." 2014 American Journal of Information
Systems 2.1): 1-5

[2] Plummer, D.C., Bittman , T.J., Austin, T., Cearley, D.W., and Smith D.M. Cloud Computing: Defining and Describing an Emerging Phenomenon Standards. 2008

[3] Buyya, R., Yeo, C., Venugopal, S., Broberg, J. and Brandic, I. "Cloud computing and emerging IT platforms: Vision, hype, and reality for delivering computing as the 5th utility." Future Generation Computer Systems, 2008 ,25(6): 599-616..

[4] MELL, P. and GRANCE, T. Draft NIST Working Definition of Cloud Computing ,2009.

[5] Sotomayor, B., Rubã®, A., IIorente, I. and Foster,I. virtual infrastructure management In private and hybrid clouds. Internet computing, IEEE, 2009 13, 5, 14-22

[6] Song, S., Ryu, K. and Da Silva, D. Blue Eyes: Scalable and reliable system Management for cloud computing. In Parallel \& Distributed Processing, 2009. IPDPS 2009. IEEE Internationa symposium on, 1-8.

[7] Vishwanath, K., Greenberg,A. And Reed, D.). Modular Data Centers: How to design Them?,2009

[8] Sriram, IA Simulation Tool Exploring Cloud- Scale Data Centres. In $1^{\text {st }}$ International Conference on Cloud Computing (CloudCom 2009), pp.381-392

[9] Buyya, R., Ranjan, R. and Calheiros, R. N. Modeling and simulation of scalable Cloud computing environments and the Cloud Sim toolkit: Challenges and opportunities. In High Performance Computing \& simulation2009. HPCS '09. International Conference on, 1-11.

[10] Pearlson, K., \& Saunders, C,Managing and using information Systems Hoboken, NJ: John Wiley \& Sons Services, 2009. ICIW '09. Fourth International Conference on 328-336

[11] www.ibm.com(2014)/blogs/cloudcomputing/h ow-does-cloud-computing-work 